\title{
Poesia y humanidades médicas desde el Cono Sur: algunas proposiciones a partir de la obra de Virna Teixeira
}

\section{| ${ }^{1}$ Francisco Gelman Constantin |}

Resumen: El artículo propone esbozar algunas direcciones futuras para los estudios literarios en el campo de las humanidades médicas del Cono Sur, a partir de una lectura cualitativa de la poesía de Virna Teixeira a la luz de las condiciones históricas de disputa sobre el conocimiento y las prácticas de la medicina. Al dejar el territorio tradicional más estrecho de la relación de escucha médicopaciente y el problema de la empatía, la palabra poética se considera un componente de un protocolo de curación, y los estudios literarios en términos de humanidades médicas, como investigación de lo que la literatura puede ofrecer para el cuidado del cuerpo.

> Palabras clave: Latinoamérica; humanidades médicas; literatura; medicina narrativa; poesía.
' Facultad de Filosofía y Letras, Universidad de Buenos Aires. Buenos Aires, Argentina (simbiosisficticia@hotmail.com). ORCID: 0000-0003-2478-0892

Recibido: 10/03/2019 Revisado: 06/05/2019 Aprobado: 25/05/2019 


\section{Introducción}

De las radiografías a las ecografías, las tomografías, los electrocardiogramas, o los videos endoscópicos, un vasto rango de imágenes integra cada día las técnicas de diagnóstico de las y los profesionales de la medicina (LE BRETON, 2002, p. 193216). Antes de ellas, en la formación de aquellos y aquellas expertas, están las imágenes didácticas, las ilustraciones médicas, sujetas a un sinfín de regulaciones sobre los modos de representar y desplegadas en un repertorio variadísimo y complejo, fruto de cada vez mayor especialización disciplinaria (WALL, 2017). Junto a ellas, sin embargo, ¿no hay que poder admitir también una multitud de otras imágenes, otras formas para la anatomía del animal humano que no son producidas por los últimos avances de la técnica científica ni reguladas por los protocolos institucionales de la ilustración médica? Imágenes singulares de los sujetos, invenciones colectivas de una cultura, legados diversos transmitidos de generación en generación circulan en las fronteras de los hospitales y las facultades de medicina, o se atreven incluso a veces a penetrarlas.

Si la antropología y la sociología de la salud llevan décadas investigando representaciones sociales del cuerpo, la salud y la enfermedad que tienen consecuencias sobre el desarrollo efectivo de las prácticas de cuidado, acaso pueda ser también un momento decisivo en la agenda contemporánea de la humanización del cuidado no solo la identificación de esos patrimonios imaginarios dados y activos, sino también la invención y la oferta de imágenes y palabras nuevas, el ingreso a las instituciones médicas de repertorios literarios y estéticos que puedan transformar los vínculos de los sujetos con su paso (o su trabajo) en esos espacios.

Este artículo indaga la pertinencia y el valor del trabajo sobre el cuerpo de las personas que pueda realizar la palabra literaria $-y$ la poética en particular- a la luz de los umbrales históricos que comprometen al Cono Sur a partir de la década de 1980. A través de un acercamiento cualitativo a los textos de la poeta y neuróloga Virna Teixeira, y su relación peculiar con las Medical Humanities británicas y la tradición psicoanalítica, el artículo tiene el objetivo de elaborar algunas proposiciones para el despliegue, a partir de esos umbrales, de estudios literarios en la perspectiva de las humanidades médicas desde la región, utilizando esa palabra poética como su programa.

Las perspectivas conceptuales e institucionales a gran escala de las humanidades médicas en el Cono Sur todavía no han sido indagadas de manera sistemática. Sin 
embargo, sí han condicionado de manera implícita y quedado sugeridas por estudios anteriores de diversas investigadoras e investigadores locales, dedicados por caso a los efectos pragmáticos del lenguaje en los procesos de curación o al sentido de los proyectos de humanización de la salud, sobre todo a partir de experiencias brasileñas (PICCARDI, 2014; GALLIAN; PONDE; RUIZ, 2012). En particular, la utilización de la poesía en el territorio de las humanidades médicas tiene antecedentes en América Latina y en otras partes, tan pronto como insumo en la formación universitaria de profesionales de la medicina -entendida como expresión estética de representaciones sociales de la medicina-, tan pronto como ejercicio de autoexploración y expresión para ser integrado a las rondas de médicos y médicas en sus residencias (MACÍAS LLANES, 2011; HOROWITZ, 1996; SHAPIRO y RUCKER, 2003). La narración literaria gozaba ya de cierto reconocimiento entre las prácticas de las humanidades médicas, bajo el punto de vista de la incorporación de la competencia para producir y recibir narraciones, o entablar afectos en la formación curricular médica (BATES; BLEAKLEY; GOODMAN, 2014; CHARON, 2006; SOUZA DE ALMEIDA, 2014; BENEDETTO, 2018; GALLIAN; BARBOSA; REGINATO, 2015; SOUSA; GALLIAN; MACIEL, 2012). Apoyándose en esos estudios previos pero avanzando en otra dirección, en este caso se trata de pensar a la poesía, en el conjunto de otras prácticas literarias y estéticas, no solo como material para las prácticas concretas de formación, diagnóstico y cura, sino como laboratorio de definición de los objetivos y perspectivas de acción de las humanidades médicas mismas, en una región del continente en la que su anclaje académico tiene un alcance todavía limitado.

\section{Desarrollo}

En la tradición anglosajona, el término "medical humanities" tiene ya siete décadas de existencia, y el desenvolvimiento institucional de las humanidades médicas, en hospitales y universidades, se ha instalado ampliamente, si bien no sin conflictos de financiamiento y objeciones a su legitimidad. Aunque algunas de las prácticas que nombra preexistían a la creación del concepto, mucha de su existencia contemporánea en el Reino Unido, Estados Unidos o Canadá (y algunos otros países que retomaron sus premisas) testimonia un vínculo históricamente específico con la reintegración de sobrevivientes de la Segunda Guerra Mundial afectados por diversas dolencias traídas de los frentes de batalla, el impulso de la bioética tras el juzgamiento norteamericano de los experimentos médicos en los campos de concentración alemanes -el Nürnberger 
Ärzteprozess del que la bioética contemporánea tomó buena parte de sus principios-y, posteriormente, la creciente mercantilización de la medicina como servicio dentro de los países capitalistas de Europa y América (BATES; BLEAKLEY; GOODMAN, 2014; MITSCHERLICH; MIELKE, 2017; ROSE, 2007).

Con esas tensiones internas y limitaciones políticas, sin embargo, las humanidades médicas se constituyeron allí como un territorio pujante de investigación intero multidisciplinaria con la capacidad de afectar de distintas maneras, menos o más directas, la práctica concreta de la medicina, en los procesos de diagnóstico y tratamiento. Si la bioética parecía allí estar destinada a establecer los márgenes morales de aquello que pudiera ser producido, vendido y comprado en el complejo biomédico, otras disciplinas dentro de las humanidades médicas se hacían sensibles a la necesidad de incorporar en la perspectiva del cuidado médico unas experiencias y valores tradicionales cuya integridad y posibilidad de transmisión las guerras mundiales habían puesto en cuestión (ROSE, 2007; JAY, 2005).

Dejando de lado el problema, patente en lo sucesivo, de que no había ninguna coalescencia necesaria entre esos dos impulsos (la nueva bioeconomía y la problemática posbélica), los efectos del orden mundial de posguerra sobre las jerarquías epistemológicas condicionaron, por otra parte, la adopción de una variante británica del psicoanálisis freudiano como matriz esencial para las humanidades médicas, con los textos e iniciativas de Michael Balint en un papel decisivo y el foco puesto en la escucha médica, con su consecuente dimensión individualizadora (CHARON; RUDNYTSKY, 2008).

Con la excepción del caso cubano -singular en la trayectoria histórica de su medicina desde la década de 1960 en muchos más sentidos-, en América Latina las humanidades médicas tuvieron un desarrollo restringido (DURIVE CALDERIUS, 2018). Si bien la Universidad de La Plata, en Argentina, parece haber sido la primera en el mundo en asignar un fondo específico a la investigación en el área, su implantación institucional en el continente resultó muy estrecha: cursos universitarios casi clandestinos (descontando las materias de bioética), seminarios o ateneos ocasionales en hospitales, revistas académicas más conocidas en otros países que en las propias facultades que las editan, programas académicos valiosísimos pero afectados de la desconexión entre las distintas facultades y entre la universidad y los hospitales. Por cierto que en los mismos países sí florecían en cambio investigaciones vastas y valiosas en antropología y sociología de salud, en un vínculo específico con 
las trayectorias de la medicina social y la salud colectiva de los años cincuenta y sesenta, y sus resultados habrían de incorporarse más adelante en la reforma de planes de estudio de las carreras de medicina, enfermería y psicología, así como habrían de crear las condiciones para políticas públicas y para modificaciones en la circulación comunitaria de saberes y sentidos en relación con esas problemáticas (COSTA; RODRÍGUEZ, 2017; FONSECA, 2005; GREGORCI, 2007; GRIMBERG, 2002; LLOVET, 1984; RÍO FORTUNA, 2010; ROCA, 2010; SPINELLI, 2004; entre muchos otros y otras).

No obstante, bajo la designación de humanidades médicas apenas se desenvolvían indagaciones en historia de la medicina y en bioética, en sí mismas muy valiosas pero con un foco y radio de acción específicos. A la creciente demanda de formación en humanidades y ciencias sociales que surgía de los planes de estudios más recientes en las carreras de medicina, enfermería y demás ciencias de la salud no respondía una expansión de los horizontes disciplinares y epistemológicos de las humanidades médicas. Pueden postularse diversos factores condicionantes de esa marginalidad, desde una desconfianza justificada ante el discurso de las humanidades médicas en su versión norteamericana por su institucionalismo en ocasiones poco crítico (en ello muy distinto de lo que la convergencia con los movimientos de pacientes provocó en el ámbito británico), hasta el predominio local de una vertiente del psicoanálisis que se entiende como anti-médica y por lo tanto socava otras posibilidades de interrogación humanística de los saberes "bio", o la discordancia entre el horizonte de la humanización del cuidado en el ámbito médico -con el legado hispánico antropológico y católico perceptible en sus variantes locales- y la objeción de la categoría normativa de lo humano en la teoría y la crítica sociales (LOZANO VICENTE, 2014; GALLIAN; PONDE; RUIZ, 2014). Se trata, con todo, de hipótesis aún especulativas.

Lo que en cambio es imposible obviar es la presencia efectiva en América Latina de condiciones favorables al despliegue de una disposición crítica respecto de las prácticas y saberes de la medicina, que habrían podido servir de fundamento a una trayectoria local más sistemática de las humanidades médicas. A partir de la indagación exploratoria de algunas obras literarias, escénicas y fílmicas del período, tal como fue emprendida en una investigación más vasta (GELMAN CONSTANTIN, 2019), fue posible enfocar en la década de 1980 la convergencia en el subcontinente de tres fenómenos de distinta naturaleza que podríamos designar 
conjuntamente como un "malestar en la medicina". En un rastreo bibliográfico conducido por la identificación retroactiva de ese umbral histórico de "malestar en la medicina" pudo establecerse las condiciones culturales relevantes que corresponden a esos tres procesos.

En primer lugar, se trata de 1980 como la década la crisis del SIDA. El estallido del SIDA y la subsecuente pandemia implicaron distintos niveles de politización de la enfermedad que determinaron umbrales de apertura de una problemática biomédica a intervenciones exteriores a las instituciones médicas profesionales y a una interrogación de los saberes por fuera de sus fronteras habituales. La enfermedad fue reconocida como un problema colectivo/público y no individual/privado; por la escala demográfica, por el papel de la sexualidad en la transmisión, por la necesidad de modos de acción educativos, por la gravitación de estereotipos culturales, el SIDA fue objeto en los ochenta de una discusión social amplia y no solamente interior a la comunidad disciplinar médica.

La organización de las personas viviendo con vih/SIDA para exigir atención médica colaboró en el desmontaje del colectivo de pacientes como receptores y receptoras pasivas de tratamiento, y las enfrentó con agentes sociales conservadores en relación con la discusión pública de la sexualidad, como la Iglesia católica. Las dificultades de la comunidad médica para ofrecer un tratamiento inmediato efectivo, por otra parte, socavaron la confianza en el saber y por ende en la autoridad de las y los profesionales médicos; al tiempo que los protocolos de intervención epidemiológica sobre los grupos sexuales disidentes despertaron alarma sobre las dimensiones moralizantes y regulatorias de la práctica médica. El origen africano del virus y su prevalencia duradera en el Tercer Mundo, a su vez, pusieron en evidencia el entrecruzamiento de los problemas biomédicos con los distintos regímenes de desigualdad social (BATES; BLEAKLEY; GOODMAN, 2014; BIRMAN, 1991; FEE; FOX, 1988; FRASCA, 2005; GUERRERO; BOUZAGLO, 2009; INGENSCHAY, 2005; MERUANE, 2012; PALMEIRO, 2011; VAGGIONE, 2013).

En segundo lugar hay que situar los efectos en lo sucesivo de la participación de médicos, médicas, parteras, enfermeros y enfermeras en las violencias de Estado de las dictaduras del Cono Sur, mucho más allá de la proliferación de metáforas organicistas en el discurso de los dictadores. En décadas anteriores el sanitarismo, el perfil del médico de los pobres (de la figura épica del médico Che Guevara a contrapartes menos célebres) y la conformación de brigadas sanitarias dentro de 
organizaciones revolucionarias habían determinado cierta disponibilidad políticosocial de la práctica especializada de la medicina en la experiencia colectiva. Este signo se trastoca con el papel de los y las profesionales de la salud dentro de la maquinaria represiva de los Estados dictatoriales (en un arco que discurre entre la participación bajo coacción y la colaboración voluntaria y diligente), sea al intervenir en sesiones de tortura para determinar umbrales de resistencia, al reavivar víctimas para continuar el procedimiento o al recomendar técnicas, o en el ocultamiento de las causas de muerte en asesinatos políticos y la apropiación de bebés.

Ante la duradera impunidad de esos actos criminales en los sistemas judiciales de los respectivos países, fueron frecuentes los tribunales éticos y/o políticos o comisiones de investigación organizadas gremialmente por los propios médicos y médicas a lo largo de los años ochenta. El conjunto de experiencias, disponibles primero en testimonios dentro y fuera de los tribunales y luego estudiadas en diversas investigaciones especializadas, conspiró contra la confianza en el espacio hospitalario como sitio neutral de tratamiento y resguardo, socavó la prevalencia del criterio de jerarquía como fundamento de autoridad dentro de las instituciones sanitarias (puesto que la obediencia había sido funcional a los proyectos genocidas), desacopló la relación entre el saber médico y las prácticas del cuidado -no todo saber médico es ejercido con fines de cuidado, y mucho del cuidado del cuerpo biológico dentro de los campos de detención y tortura no es ejercido por profesionales de la salud, sino por compañeros y compañeras de cautiverio-, y desnaturalizó la experiencia del dolor dentro de la institución médica (CONADEP, 1985; COMISSÃO NACIONAL DA VERDADE, 2014; CALVEIRO, 2001; ACTIS, LEWIN et al., 2001; RICO, 2009; REY TRISTÁN, 2007; RIQUELME, 1995).

En tercer lugar se trata de los desarrollos locales de experimentos de desmanicomialización y sus vínculos con los movimientos de antipsiquiatría. Si bien las primeras experiencias de comunidades terapéuticas no manicomiales en el continente-como aquellas asociadas a los nombres de Raúl Camino o Alfredo Moffat en Argentina o al de Héctor Cruz en Colombia- tuvieron lugar a finales de los años sesenta y principios de los setenta, la politización del cuidado psiquiátrico encontró un momento singular en la década del ochenta tras la interrupción que supusieron las políticas de salud mental de las dictaduras y movimientos varios de aislamiento y socavamiento por parte del Estado (BARRACO, 2007; MARCOS, 1983). 
A lo largo de la década del setenta se tradujeron en América Latina al español y al portugués las principales obras de la antipsiquiatría provenientes de Estados Unidos y Europa, al tiempo que esa tradición entraba en contacto con las críticas feministas a la institución psiquiátrica; en 1978 se reunió en Cuernavaca el IV Encuentro Internacional de Alternativas a la Psiquiatría y en 1981 se reunió allí mismo el I Encuentro Latinoamericano y V Encuentro Internacional -durante el cual fue, a su vez, objeto de denuncia y análisis específico la colaboración de profesionales de la salud mental en los estados represores-(TOMES, 1994; MARCOS, 1983). A lo largo de la década proliferaron además las organizaciones de pacientes, expacientes o "sobrevivientes de la psiquiatría", y se expandió la problematización de la normatividad sexual en las doctrinas y prácticas psiquiátricas y psicológicas (CEAMADRID; CASTILLO-PARADA, 2016; MARCOS, 1983; DI SEGNI, 2013).

Aunque estaban lejos de lograr sus objetivos, en los ochenta la antipsiquiatría y la desmanicomialización se instalaron sin embargo definitivamente en el continente y se trasladaron, del ideario de algunas experiencias señeras y la contestación radical, a las condiciones generales de institucionalización/ desinstitucionalización del cuidado psiquiátrico (BAULEO, 1983; DUARTE JÚNIOR, 1983; LOUGON, 1993; CEAMADRID; CASTILLO-PARADA, 2016); con ello, la crítica del autoritarismo en la administración del cuidado médico, la incorporación de profesionales no médicos en las prácticas, el enfoque comunitario y la sutura entre técnicas de cuidado y dispositivos culturales se incorporaron a las políticas de salud mental.

A falta de humanidades médicas a gran escala, esas condiciones de "malestar en la medicina" sí favorecieron en América Latina -junto con la maduración continua de la antropología y sociología de la salud- la multiplicación de intervenciones literarias y artísticas sobre los saberes y prácticas médicas. La lista de autores y autoras literarias, y artistas en general es interminable; la cantidad de obras, inmensa. A los efectos de explorar el sentido de algunas de estas irrupciones "impertinentes" en el terreno biomédico, en una investigación que excede las fronteras de este artículo, ha sido cuestión de comprender las concepciones de lo literario que justificaban esa ubicuidad, a partir de las obras de Ercole Lissardi (Uruguay), Emilio García Wehbi (Argentina), Fernando Vallejo (Colombia/ México), y João Gilberto Noll y Virna Teixeira (Brasil) (GELMAN CONSTANTIN, 2019). En su conjunto, se ha tratado todavía de una investigación en el nivel básico, sobre los materiales estéticos mismos, que sugiere modos posibles de uso de esos materiales en espacios 
concretos de cuidado médico todavía a ser ensayados. Entendido que el desarrollo de las humanidades médicas como un proyecto multidisciplinario amplio bajo una perspectiva latinoamericana todavía es un trabajo en mayor medida por hacer, apenas se ha abordado obras literarias y escénicas para interrogar a ellas mismas sobre vías hipotéticas para una intervención institucional más sistemática sobre las prácticas de la salud. La indagación específica de las condiciones institucionales que las hagan posibles es el próximo avance necesario.

De la investigación más vasta en la que se inserta este artículo, entonces, proviene un abanico de modos de intervención pensables a partir de las obras, de acuerdo con cómo comprenden ellas mismas la relación entre la biomedicina y la palabra literaria. No se trata tanto, por ende, de tomar textos literarios existentes como "formas de conocimiento" que testimonien de una manera más elocuente experiencias históricas en torno a la salud (LAPLANTINE, 1999, p. 33), sino más bien para imaginar a partir de ellos formas de acción en el campo práctico del cuidado que los tomen como herramienta. En ese sentido hemos hablado de cinco posibilidades distintas, que en el marco de este artículo solo será posible nombrar, pero cuyas denominaciones acaso alcancen a sugerir algunas de las direcciones exploradas. Se ha tratado de a) el objeto literario como un fetiche que ofrezca protección a los cuerpos expuestos en el espacio hospitalario; b) la escritura literaria como sincronización/desincronización de los tiempos biológicos, subjetivos y administrativos del cuidado; c) los enunciados literarios como interferencias sobre el discurso médico en su capacidad de decisión sobre alternativas terapéuticas y de final de vida; d) el artefacto literario como prótesis en la humanización del cuidado; y e) la palabra literaria como parte de un protocolo de cura. En este artículo expondremos solo esta última modalidad (e), en la que la poesía de Teixeira nos sugiere cierto uso de la palabra en un marco terapéutico.

En la tradición anglófona la literatura y los estudios literarios encuentran su lugar en las humanidades médicas fundamentalmente a través de la práctica de la "medicina narrativa", que promueve competencias de escucha, lectura y escritura puestas en función de la construcción de un historial médico más comprensivo y del mejoramiento de las técnicas de diagnóstico, incluso si su fundadora, Rita Charon, esperaba que esas narrativas tuvieran repercusiones de muchas más dimensiones (CHARON; RUDNYTSKY, 2008; MARINI, 2016; NUNES; CASTELLANOS; BARROS, 2010). Situar las coordenadas a partir de una escritura poética implica forzosamente ciertos desplazamientos respecto de esa tradición. Más que un simple 
ahorro de tiempo en la instrucción de valores humanistas (porque un poema es más corto que una novela; cfr. HOROWITZ, 1996), el despliegue de unas humanidades médicas latinoamericanas a partir de la poesía sienta el camino para una concepción distinta de su ejercicio, que interroga sus presupuestos, según veremos a continuación.

Las Medical Humanities atribuían con justicia a las novelas y cuentos clásicos de los que se servía la medicina narrativa (con el realismo decimonónico a la cabeza) la estructura discreta de un relator que transmite su historia a un oyente, comparable legítimamente a la construcción de la historia personal en la entrevista clínica (cfr. SCHLEIFER; VANATTA, 2013). La poesía de Virna Teixeira abre la posibilidad de dispersar la escena del cuidado de los cuerpos respecto de la interlocución lineal del vínculo médico-paciente, el diálogo entre individuos, porque la escena de la escritura poética no coincide con la escena de la narración tal como la describían las humanidades médicas anglosajonas.

Los poemas de Teixeira despliegan entre voces de origen desconocido un "mapa dolorido do corpo", según la sugerencia de un poema sin título incluido en el volumen Trânsitos (2009, p. 37) y ese anonimato desarma la conversación entre sujetos individuales hacia una circulación colectiva de palabras. Sin profesión de "yo" o "usted", la presentación de un cuerpo:

de bruços, o impacto

das pedras quentes e óleo

amortece - o mapa

dolorido do corpo

um spa na áfrica

ou em jaipur

ayurvédica, meridianos

não há retorno

apos o nigredo

solo el magma de las horas

descompuestas - en ebullición de bruces el impacto de piedras calientes, óleo adormece - el mapa

dolorido del cuerpo

un spa en áfrica

o en jaipur

ayurvédica, meridianos

no hay retorno

tras la nigredo

só o magma das horas

decompostas - em ebulição 
El dolor corporal se abre entre los meridianos del ayurveda y los meridianos de la Tierra; solo a través de la palabra es local (es un dolor 'acá'), pero en la palabra misma se aparta de un lugar propio ('mío' o 'suyo') o de aquietarse en un continente o en una ciudad. De una palabra a otra y en su ausencia (el blanco de página, el guion tipográfico, el silencio en la lectura) se oferta una cartografía a cualquiera y desde cualquiera, que van dibujando las letras o los sonidos. Mientras el cuerpo lastimado se dispone para el cuidado, horizontal en una camilla o cama de un lugar incierto, se prepara para una terapia, remedios y un masaje, su forma se redibuja, ¿en manos de quién o quiénes? La singularidad irreductible de una carne que duele no podría desaparecer, ni ser homogeneizada con cuerpos serializados; pero su mudanza curativa no coincide con la simple interacción entre dos, como en la "two bodies psychology" inglesa. Una verdadera transformación alquímica (en la fase de la nigredo, en que el barro fluye hacia el oro; en esa química fantástica de los tejidos, las napas históricas se superponen con la etnografía; cf. LE BRETON, 2002, p. $86,182)$ se inscribe no sobre las zonas señaladas por una radiografía, sino sobre ese mapa del dolor delineado en las palabras que circulan, desde fuentes múltiples y sin nombre, haciendo lugar a otra "retórica" encarnada de la curación (CSORDAS, 2002: 25, 77). El nombrar del dolor, como sugiere la antropología (LE BRETON, 1999, p. 29), compromete fundamentalmente su experiencia; la materia verbal concreta y su fuente inscriben diferencias fundamentales.

La palabra poética no subsume un decir del o la paciente ni uno de la o el profesional de la salud, incluso si quien escribe materialmente las palabras de poemarios como Distância o Trânsitos es una médica neuróloga, ella también, probablemente, en algún u otro momento de su vida paciente. Aparece en cambio como suspendida y anónima en el espacio, acaso un poco como aquellas reproducciones de cuadros -las más de las veces panoramas impresionistas, floreros de Van Gogh o maternidades de épocas diversas en las salas oportunas- que cuelgan de las paredes de clínicas y consultorios. Pero si esas láminas deslucidas cumplen funciones decorativas, alegran o neutralizan el espacio, lo aquietan, la palabra poética invade la escena médica con especial dinamismo, se desplaza y horada sus fronteras. Esa actividad subrepticia con la que ingresa es la propia de un componente de una técnica del cuidado.

La idea de un cuidado de esta especie, de una "cura con palabras", tiene una genealogía memorable. Se escribe en inglés, "talking cure", pero en un inglés hablado como una lengua extranjera y extrañada: el inglés que habla la escritora, activista 
social y feminista alemana Bertha Pappenheim en aquellos célebres episodios histéricos en los que olvidaba su lengua materna (FREUD y BREUER, 1992; DIDI-HUBERMAN, 2007; MITCHELL, 2000), olvido de la lengua propia que desmonta el yo y también rehúsa el lenguaje más comprensible para quien escucha. Registrado en los escritos de Freud como Anna O., el paso de Pappenheim por el psicoanálisis es un momento decisivo para el pensamiento de una enfermedad compuesta por palabras y por eso mismo sensible a su efecto también para la cura. El cuerpo histerizado es un cuerpo habitado por decires que no le pertenecen plenamente, que no pueden venir de inmediato firmados por ese sujeto. Una parte del cuerpo insensible, dolorosa, paralizada o afectada de un tic - una extremidad, un músculo de la cara, el estómago- está como colonizada por una experiencia verbalizable, por una formación heterogénea de palabras, afectos e imágenes; la o el histérico "más que oír [la] voz, la sient[e] en toda la carne", en términos de Julia Kristeva (2008, p. 597; cf. LE BRETON, 1999, p. 11), y por esa razón responde igualmente a la cura con palabras.

No podría sino extrañarse también la lengua (y la tradición) inglesa cuando la incorpora subrepticiamente Teixeira en sus propios poemas, o cuando la traduce de poemas de Edwin Morgan, Richard Price y otros autores británicos. Y singular también es su lectura de la talking cure cuando titula uno de sus blogs freudwasaneurologist.com, resolviendo reivindicar el legado vienés, pero en oposición abierta a aquellos que lo hacen ajeno y contradictorio con lo más actual de la práctica médica. En ese discreto gesto de titulación aparece compactado también el desvío que habrá de introducir cuando se traslade a Londres en 2014 para estudiar Medical Humanities en el King's College. Y es que su escritura poética (y ensayística) abre nuevos caminos para las humanidades médicas desde el Cono Sur, incluso cuando se escribe en migraciones sucesivas y a caballo entre varias lenguas.

Como los "giros lingüísticos" que habitan a las y los histéricos, la palabra poética de los textos de Teixeira aparece suspendida en una tercera persona, que no es ni de quien convalece ni de quien lo o la trata; o, mejor, en un tercer lugar que acaso no es en absoluto una persona y por lo tanto es irreductible a la "relación médicopaciente" de las humanidades médicas anglosajonas, incluso si está adentro del cuerpo, como "palabras en tus ojos, espejos" (TEIXEIRA, 2005, p. 35). Desde ese lugar tercero, ajeno, las palabras pueden herir, dejar "pequeños hematomas", como en el poema "Conversa" (ibíd., p. 24), que más que por metáforas han de ser tomados 
por pequeños desplazamientos metonímicos dentro del terreno de la enfermedad y las afecciones del cuerpo o, en el límite, por hematomas completamente literales -a tales grados llegan a veces las formas de la Konversion-. Pero esas mismas palabras también pueden sanar, incorporarse a un protocolo de cura, según anuncia el poema "Ausência" (ibíd, p. 39):

o que as palavras

escondiam

de delicadeza

no meio da violência

o amor

na voz que não cabe

neste silêncio

e a fotografia

sobre a mesa

nunca enviada

são as palavras

que sofrem

aqui, onde tudo

termina. lo que escondían

las palabras

de delicadeza

en medio de violencia

el amor

en la voz que no cabe en

este silencio

y la fotografía

sobre la mesa

nunca enviada

son las palabras

que sufren

aquí, donde todo

termina.

En las palabras se esconde una "delicadeza", un "amor" tal que son ellas las que "sufren", a un palmo de distancia del sujeto, y no él o ella misma, olvidado u olvidada siquiera de una parte de su pesar. La parquedad verbal de estos poemas tempranos de Teixeira es consustancial con sus operaciones de delicadeza: reducir la palabra al mínimo indispensable, sin que sea cuestión de secreto sino de dejar el espacio oportuno para algo de otro orden, una apertura a lo por venir, a lo tentativo y mudable. La suspensión del envío y los puntos suspensivos convergen en 
un mismo gesto, en el que esconder no es sinónimo de ocultar sino de guarecer lo ajeno. En el nombre de afectos, en las voces negadas, en participios sin agentes de acción ("enviada") se presume un sujeto en la cercanía, beneficiario posible de esa distancia curativa, pero su lugar queda vacante, disponible a cualquiera. Un "deseo [...] de [...] palabra” habrá de ser el deseo de una exterioridad o apartamiento, la poesía como la posibilidad de dislocar lo que de otro modo debería guardar dentro suyo el sujeto convaleciente. Ni discurso autorizado del médico ni historia íntima del paciente a la que ofrecer una escucha empática, la palabra poética se presenta como un recurso terapéutico.

Tal como -con Freud en el título del blog-el psicoanálisis es reincorporado a la neurología y no enfrentado a ella, la lengua poética de Teixeira no elige apartarse y oponerse a la medicina, sino visitarla, y así se entreteje con las expresiones de la anatomofisiología ("quadríceps", "hipocampo", “epiderme”, “conjuntivas") y aquellas que nombran medios del tratamiento ("suturas", "gaze”, "desfibrilador") para ubicarse, acaso, entre ellos. Respetuosa ante la neurología, la antisepsia o las radiografías, la poesía no se adjudica la omnipotencia curativa de un encantamiento, pero sí, más modestamente, reclama su lugar junto a esos otros medios y explora aquella parte del cuidado de los cuerpos que solo ella puede realizar del mejor modo.

Hasta aquí el alcance propio de esta exploración, todavía en el nivel de los fundamentos literarios de un trabajo por venir, que señalan en la dirección de dispositivos de lectura y escritura que se apoyen en los sentidos de cuidado que se abren en el juego entre palabra y silencio o blanco (con sus suspensos, sus imágenes laterales y sus envíos pendientes), y en el efecto de anonimato de la voz que permite cierta escritura poética, apartándose de la emisión autorizada del médico tanto como de la historia personal (confesional) del paciente. Su traducción en iniciativas específicas en el terreno hospitalario o de la formación universitaria de los y las profesionales de la salud requiere de su integración con la indagación antropológica y sociológica de las instituciones particulares en las que se las vaya a llevar adelante. Con todo, para enriquecer la comprensión de algunas de las posibilidades prácticas que este artículo quiere anticipar, en el Anexo 1 al final de este artículo se ha incluido un ejemplo de propuesta posible consecuente con los parámetros desarrollados aquí.

Allí donde las humanidades médicas todavía tienen -en América Latina y en particular el Cono Sur- un campo considerable de desarrollo pero ha habido condiciones históricas singulares para la maduración de una disposición crítica respecto 
de la biomedicina, a partir de lo que sugiere la poesía de Teixeira es posible tomar a la literatura y las artes como partitura de este desarrollo por venir, para una humanización del cuidado que no dependa de universales espirituales sesgados de colonialismo y homogeneización, ni de la oferta ilimitada de servicios que pone a disposición el mercado de la medicina en los países capitalistas. La biomedicina del Cono Sur, expuesta a todos esos peligros, abre también sin embargo un espacio singularmente propicio para experimentar con nuevos protocolos de cura, que no renieguen -en un gesto de romanticismo insensato- de los últimos desarrollos biocientíficos, pero sí entablen un vínculo creativo con las técnicas de la palabra, insistiendo sobre el gesto hacia una "clínica ampliada" (PORTUGAL; MEZZA; NUNES, 2018).

\section{Consideraciones finales}

Este artículo procuró situar los umbrales históricos de una relación crítica con las prácticas y los saberes de la biomedicina en el Cono Sur, que identificó con el desarrollo local de la crisis del SIDA, la colaboración de profesionales de la salud en las violencias de Estado de las dictaduras y los despliegues locales de la antipsiquiatría y la desmanicomialización. A partir de ellos y en ausencia de un desarrollo sistemático de las humanidades médicas en la región (sobre cuyo bloqueo se expusieron algunas hipótesis apenas tentativas), se propuso buscar la proyección futura para su crecimiento no en las instituciones académicas sino en la producción literaria y estética, y más específicamente en la poesía.

A partir de una aproximación a los poemas de Virna Teixeira, se intentó no simplemente tener acceso a una experiencia delicada y precisa del paso por hospitales, clínicas, psiquiátricos, sino en particular delinear el rol que puede caberle a unos estudios literarios en humanidades médicas pensados desde el Cono Sur, como suplemento de la antropología y sociología de la salud florecientes. De acuerdo con el desarrollo de este artículo, ese rol fue elaborado como el de formular a la propia literatura, dentro y fuera de la poesía, la pregunta por lo que ella misma puede aportar para el cuidado y la sanación de los cuerpos. Trascendiendo la escena más estricta del vínculo médico-paciente y el problema de la empatía, aquella posibilidad de las humanidades médicas apuntó a una relación con los anhelos y sufrimientos inherentes al espacio médico que las palabras pueden alterar y desplazar, apareciendo no necesariamente como componente de un diálogo, sino como voces que habitan 
materialmente el espacio hospitalario, como una técnica de cuidado disponible para todos los sujetos que lo habitan.

Si las consideraciones motivadas por el análisis de la poesía de Teixeira tienen todavía mucho de elusivo y abstracto, siquiera parte de ello debe corresponder a su incorporación como el programa de un cuidado por venir, forzosamente abierto. Allí donde la literatura y las artes interpelan a la biomedicina sobre sus saberes y prácticas, proyectan también una modalidad suplementaria de acción sobre los cuerpos que la reinvención de las humanidades médicas desde el Cono Sur podría estar destinada a realizar.

\section{Referencias}

ACTIS, M.; LEWIN, M. et al. Ese infierno. Conversaciones de cinco mujeres sobrevivientes de la ESMA. Buenos Aires: Sudamericana, 2001.

BARRACO, Á. et al. Desmanicomializar. Pasado y presente de los manicomios. Topia, Buenos Aires, 2007. Disponible en: <https://www.google.com/urlssa=t\&rct=j\&q=\&esrc=s\&source=web\&cd= $1 \& \mathrm{cad}=$ rja\&uact $=8 \&$ ved $=2$ ahUKEwiryJjhmPbgAhWdFLkGHYJqCewQFjAAegQICRAB $\&$ url=https\%3A\%2F\%2Fwww.topia.com.ar\%2Farticulos\%2Fdesmanicomializar-pasado-y-presentede-los-manicomios \&usg=AOvVaw0qbZuwg_Mu-PbMDA8c0w__>. Acceso: 7. jun. 2015.

BATES, V.; BLEAKLEY, A.; GOODMAN, S. (Eds.). Medicine, health and the arts: approaches to Medical Humanities. London/ New York: Routledge, 2014.

BAULEO, A. Laing y la antipsiquiatría. En: LAING, A. V. Antipsiquiatría y contracultura. Madrid: Fundamentos, 1983.

BIRMAN, J. A physis da saúde coletiva. Physis, Rio de Janeiro, v. 1, n. 1, p. 7-11, 1991.

CALVEIRO, P. Poder y desaparición. Los campos de concentración en Argentina. Buenos Aires: Colihue, 2001.

CEA-MADRID, J. C.; CASTILLO-PARADA, T. Materiales para una historia de la antipsiquiatría: balance y perspectivas. Teoría y Crítica de la Psicología, n. 8, p. 169-92, 2016.

CHARON, R. Narrative Medicine. Honoring the Stories of Illness. Oxford/ New York: Oxford University Press, 2006.

CHARON, R.; RUDNYTSKY, P. L. Psychoanalysis and Narrative Medicine. New York: University of New York, 2008.

GALLIAN, D. M. C.; BARBOSA, L. R.; REGINATO, V. Literatura e o ensino da filosofia na graduação em enfermagem. Revista Internacional de Salud, Bienestar y Sociedad, v. 2, n. 1, p. 63-71, 2015. 
COMISSÃO NACIONAL DA VERDADE. Relatório. Brasília: CNV, 2014.

CONADEP. Nunca más. Informe de la Comisión Nacional sobre la Desaparición de Personas. Buenos Aires: Eudeba, 1985.

COSTA, F.; RODRÍGUEZ, P. (comps.). La salud inalcanzable. Biopolitica molecular y medicalización de la vida cotidiana. Buenos Aires: Eudeba, 2017.

CSORDAS, T. J. Body/meaning/healing. New York: Palgrave Macmillan, 2002.

BENEDETTO, M. A. C. Narrativas em cuidados paliativos: um instrumento para ensinar e cuidar. Archivos en Medicina Familiar, v. 20, n. 2, p. 85-94, 2018.

DIDI-HUBERMAN, G. La invención de la histeria [fr. 1982]. Trad. de T. Arias y R. Jackson. Madrid: Cátedra, 2007.

DI SEGNI, S. Sexualidades. Tensiones entre la psiquiatría y los colectivos militantes. Buenos Aires: Fondo de Cultura Económica, 2013.

DUARTE JÚNIOR, J. F. A política da loucura (a antipsiquiatria). Campinas-SP: Papirus, 1983.

GELMAN CONSTANTIN, F. Formas de lo viviente en América Latina (1980-2018). Incursiones literarias en una escena biomédica. Tesis (Doctorado en Literatura) - Universidad de Buenos Aires, Buenos Aires, Argentina, 2019.

NUNES, E. D.; CASTELLANOS, M. E. P.; BARROS, N. F. A experiência com a doença: da entrevista à narrativa. Physis, v. 20, n. 4, p. 1341-1356, 2010.

DURIVE CALDERIUS, N. F. Breve recuento histórico sobre la Universidad de Ciencias Médicas de La Habana. Humanidades Médicas, v. 18, n. 1, p. 154-170, 2018.

FEE, E.; FOX, D. M. (Eds.). AIDS: The Burdens of History. Berkeley: University of California Press, 1988.

FONSECA, C. Paternidade brasileira na era do DNA: a certeza que pariu a dúvida. Cuadernos de Antropología Social, n. 22, p. 27-51, 2005.

FRASCA T. AIDS in Latin America. New York: Palgrave, 2005.

FREUD, S.; BREUER, J. Estudios sobre la histeria [al. 1895]. Trad. de J. L. Etcheverry. Buenos Aires: Amorrortu, 1992.

GALLIAN, D.; PONDE, L. F.; RUIZ, R. Humanização, Humanismos e Humanidades: problematizando conceitos e práticas no contexto da saúde no Brasil. Revista Internacional de Humanidades Médicas, v. 1, n. 1, 2012.

GREGORIC, J. J. Un estudio antropológico del proceso de organización y la politización de la salud entre personas viviendo con el Vih. Tesis (Doctorado en Antropología) - Universidad de Buenos Aires, Buenos Aires, 2007. 
GRIMBERG, M. Entre saber y actuar: relaciones de género y prevención del vih-sida en mujeres de sectores populares de zona sur de la Ciudad de Bs. As. Runa, n. XXIII, p. 173-195, 2002.

GUERRERO, J.; BOUZAGLO, N. Excesos del cuerpo. Ficciones de contagio y enfermedad en América Latina. Buenos Aires: Eterna Cadencia, 2009.

HOROWITZ, H. W. Poetry on rounds: a model for the integration of humanities into residency training. Lancet, n. 347, p. 447-9, 1996.

INGENSCHAY, D. Hemispheric Looks at Literary AIDS Discourses in Latin America. Iberoamericana, v. V, n. 20, p. 141-56, 2005.

JAY, M. Songs of experience. Berkeley: University of California, 2005.

KRISTEVA, J. Thérèse mon amour. Paris: Fayard, 2008.

LAPLANTINE, F. Antropología de la enfermedad. Trad. de M. A. Ruocco. Buenos Aires: Del Sol, 1999.

LE BRETON, D. Antropología del dolor. Trad. de D. Alcoba. Barcelona: Seix Barral, 1999. . Antropología del cuerpo y modernidad. Trad. de P. Mahler. Buenos Aires: Nueva Visión, 2002.

LLOVET, J. J. Servicios de salud y sectores populares. Los años del Proceso. Buenos Aires: CEDES, 1984.

LOUGON, M. Desinstitucionalização da assistência psiquiátrica: uma perspectiva crítica. Physis, v. 3, n. 1, p. 137-162, 1993.

LOZANO VICENTE, A. Sobre la bioética iberoamericana: una paradoja. Humanidades Médicas, v. 14, n. 3, p. 570-588, 2014.

MACÍAS LLANES, M. E. Ciencias Sociales y Humanísticas en la formación médica. Humanidades Médicas, v. 11, n. 1, p. 18-44, 2011.

MARCOS, S. (coord.). Manicomios y prisiones. Aportaciones críticas del I Encuentro Latinoamericano y V Internacional de Alternativas a la Psiquiatría. México D. F.: RedEdiciones, 1983.

MARINI, M. G. Narrative medicine. Bridging the gap between evidence-based care and Medical Humanities. New York: Springer, 2016.

MERUANE, L. Viajes virales. La crisis del contagio global en la escritura del sida. Santiago de Chile: Fondo de Cultura Económica, 2012.

MITCHELL, J. Mad men and medusas. Reclaiming hysteria. New York: Basic Books, 2000.

MITSCHERLICH, A; MIELKE, F. Medizin ohne Menschlichkeit. Frankfurt am Main: Fischer; 2017. 
PORTUGAL, C.; MEZZA, M.; NUNES, M. A clínica entre parênteses: reflexóes sobre o papel da arte e da militância na vida de usuários de saúde mental. Physis, v. 28, n. 2, p. e280211, 2018. PALMEIRO C. Emergencia del Sida. En: Desbunde y felicidad. Buenos Aires: Título, 2011.

PICCARDI, T. Transformando sofrimento em narrativa e narrativa em uma nova vida. Revista Internacional de Humanidades Médicas, v. 3, n. 1, 2014.

REY TRISTÁN, E. (ed.). Memorias de la violencia en Uruguay y Argentina. Santiago de Compostela: Universidad de Santiago de Compostela, 2007.

RICO, Á. Prácticas estatales criminales en dictadura y relaciones sociales degradadas en democracia, Uruguay. En: FEIERSTEIN, D. (Ed.). Terrorismo de estado y genocidio en América Latina. Buenos Aires: Prometeo, 2009. p. 141-160.

RÍO FORTUNA, C. A. del. “...El cierre de su etapa reproductiva”. Etnografía de la política pública a la anticoncepción quirúrgica femenina en la ciudad de Buenos Aires. Tesis (Doctorado en Antropología) - Universidad de Buenos Aires, Buenos Aires, 2010.

RIQUELME, H. Entre la obediencia y la oposición: los médicos y la ética profesional bajo la dictadura militar. Caracas: Nueva Sociedad, 1995.

ROCA, A. Fragmentos, fronteras y cuerpos incógnitos. Una mirada antropológica sobre la producción y criopreservación de vida en el laboratorio. Tesis (Doctorado en Antropología) Universidad de Buenos Aires, Buenos Aires, 2010.

ROSE, N. The Politics of Life Itself. Biomedicine, Power, and subjectivity in the twenty-first century. Princeton/ Oxford: Princeton University Press, 2007.

SCHLEIFER, R.; VANNATTA, J. B. The chief concern of Medicine. The integration of Medical Humanities and narrative knowledge into medical practices. Ann Arbor: University of Michigan Press, 2013.

SHAPIRO, J.; RUCKER, L. Can poetry make better doctors? Teaching the Humanities and Arts to medical students and residents at the University of California, Irvine, College of Medicine. Acad Med, n. 78, p. 953-957, 2003.

SOUSA, M. S. A.; GALliAN, D. M. C.; MACIEL, R. M. B. Humanidades médicas no Reino Unido: uma tendência mundial em educação médica hoje. Rev Med., Sáo Paulo, v. 91, n. 3, p. 163-173, 2012.

SOUZA DE ALMEIDA, C. C. Antropologia dos afetos em Nelson Rodrigues no laboratório de humanidades: uma experiência humanizadora na saúde. Revista Internacional de Humanidades Médicas, v. 3, n. 2, p. 13-21, 2014.

SPINELLI, H. (comp.). Salud colectiva. Cultura, instituciones y subjetividad. Epidemiología, gestión y políticas. Buenos Aires: Lugar, 2004. 
TEIXEIRA, V. Distância. Rio de Janeiro: 7 Letras, 2005.

Trânsitos. São Paulo: Lumme, 2009.

TOMES, N. Feminist histories of Psychiatry. En: MICALE, M. (Comp.). Discovering the history of psychiatry. New York: Oxford University Press, 1994. p. 348-383.

VAGGIONE, A. Literaturalenfermedad. Escrituras sobre sida en América Latina. Córdoba: Centro de Estudios Avanzados, 2013.

WALL, S. The Language of Comics in Medical and Bioscientific Communication. En: JORNADAS STORIES OF ILLNESS. Disability in Literature and Comics. Intersections of the medical, the personal and the cultural. Berlin, 27-29 de octubre de 2017. 


\section{Resumo}

Poesia e humanidades médicas no Cone Sul: algumas proposiçôes a partir da obra de Virna Teixeira

$\mathrm{O}$ artigo propóe-se a delinear algumas direçōes futuras para os estudos literários no campo das humanidades médicas do Cone Sul, a partir de uma leitura qualitativa da poesia de Virna Teixeira à luz das condiçōes históricas de disputa sobre o conhecimento e as práticas da medicina. Deixando o território tradicional mais restrito da relaçáo de escuta entre médico e paciente e o problema da empatia, a palavra poética é pensada como um componente de um protocolo de cura, e os estudos literários em termos das humanidades médicas, como a investigação do que a literatura pode oferecer para o cuidado dos corpos.

> Palavras-chave: América Latina; humanidades médicas; literatura; medicina narrativa; poesia. 


\section{Abstract}

Poetry and medical humanities in the

Southern Cone: some propositions from Virna

Teixeira's work

Through a qualitative reading of Virna Teixeira's poetry in the light of the historical conditions of struggle over the knowledge and practices of medicine, we suggest some possible lines of future development for literary scholarship in the Medical Humanities from the Cono Sur. Beyond the traditional narrower boundaries of the listening relationship between doctor and patient and the issue of empathy, the poetic word is brought forth as a part of a therapeutic protocol, while literary studies in the way of the Medical Humanities appear as the investigation of that which literature has to offer for the care of the bodies.

Keywords: Latin America; Medical Humanities; literature; narrative medicine; poetry. 


\section{ANEXO 1: Una práctica posible de intervención poética del hospital}

Como quedaba señalado en el artículo, la elaboración concreta de un protocolo de cuidado (o un programa educativo) que incorpore la perspectiva que se buscó defender a partir de la poesía de Virna Teixeira requiere la articulación de esta investigación literaria en un proyecto colectivo y multidisciplinario que -entre otras dimensiones- ofrezca un acercamiento etnográfico y un análisis institucional del sitio particular y los sujetos particulares a los que esté dirigido. Sin embargo, de manera ilustrativa, ofrezco en este Anexo el ejemplo de una práctica concreta ideada en función de este trabajo, que proviene de cierta "literalización" de uno de los poemas considerados en el Desarrollo.

La intervención está concebida como una herramienta hospitalaria dentro de un proceso de tratamiento prolongado, ya sea en el marco de una internación o en el cuidado de una o un paciente crónico. Su insumo fundamental es un cuadernillo compuesto por una antología poética (varios textos de Teixeira sería candidatos ideales a integrarla; lo mismo puede decirse de algunos poemas de Vicente Luy, Emilio García Wehbi y Gabo Ferro o Tamara Kamenszain, por ejemplo) y una cantidad de copias de una placa como la que ofrecemos en la figura 1.

Figura 1. Esquema de página: mapeo y escansión

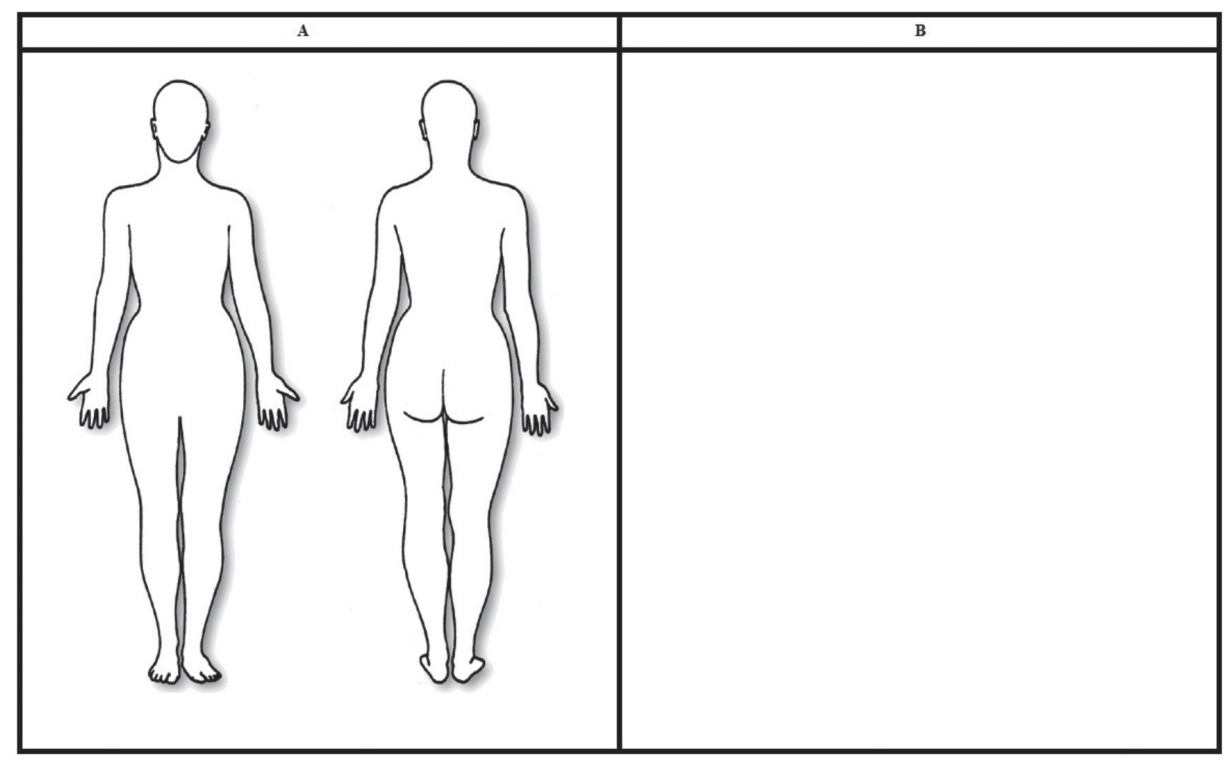


La página está compuesta por dos secciones, que llamo "zona de mapeo" (A) y "zona de escansión” (B). En la zona de mapeo hay un esquema corporal como aquellos utilizados en consultas dermatológicas o kinesiológicas, así como en ciertos dispositivos de medicina intercultural. Entendido que ningún esquema corporal carece de marcas sexuales y/o genéricas, etarias, étnicas, de talla, etcétera, debería haber cuadernillos con distintos esquemas (en el caso de internaciones cuyo propio desarrollo suponga cambios significativos en la imagen corporal, cabría considerar incluso que un mismo cuadernillo incluyera esquemas distintos entre sí). La zona de escansión es un espacio en blanco.

El cuadernillo sería ofrecido a la o el paciente en el hospital o clínica en el comienzo del tratamiento o la internación, quien elegiría un esquema corporal acorde a su percepción o deseo. A los efectos de distinguir el cuadernillo tanto de los formularios burocráticos como de la anamnesis médica, acaso no debería ser otorgado por la o el médico ni por el personal administrativo; podría estar en manos del personal de enfermería o, dado el caso, de profesionales de las humanidades o ciencias sociales que integraran el dispositivo hospitalario.

La propuesta a partir del cuadernillo estaría compuesta de diversas fases recursivas. Por un lado, la fase de lectura de la antología está concebida a los efectos de ofrecer una entrada fluida a las relaciones entre la experiencia corporal en la convalecencia u hospitalización y la palabra literaria, así como estimular las fases de escritura. La expectativa es la de ofrecer un repertorio de maneras diferentes de escribir el cuerpo, potencialmente ilimitadas pero de las que la antología ofrecería un pequeño conjunto-muestrario.

La primera fase de escritura tendría lugar en la "zona de mapeo". El o la paciente tendría como tarea escribir en el cuerpo palabras significativas que se le aparecieran como parte de su experiencia; esas palabras corresponderían tanto a invenciones personales, cuanto al registro de expresiones escuchadas del personal de salud, de sus familiares o amistades, o del contacto con objetos culturales (mediáticos, artísticos, etcétera) y entrarían apuntadas sobre alguna región del cuerpo, o bien suspendidas en el contorno blanco que rodea los cuerpos dentro del cuadrado de la zona A. Se podría utilizar diferentes colores en la notación de las palabras, que permitirían inscribir diferencias según su origen (quién las dijo o dónde se las leyó o escuchó), según los afectos con los que estuvieran conectadas o según su importancia, entre otras razones. Una palabra podría ser conectada por líneas con otras, acaso como aquellos 
"meridianos" del poema de Teixeira, estableciendo vínculos de distinta naturaleza entre ellas y las regiones corporales en las que están escritas. Esos meridianos, como conexiones tentativas, abrirían el camino a la segunda fase de escritura, en la "zona de escansión”, en la que esas palabras serían organizadas con otras en escrituras poéticas lineales, reordenadas o redispuestas para hacer aparecer otra versión de la experiencia, actual, pasada o posible.

El o la paciente podría decidir entregar algunas de las hojas de mapeo y escansión a otras personas que incluyera en su experiencia de cuidado (profesionales o personas de su entorno afectivo) para que ellas mismas también participaran directamente del trabajo de enunciación y poetización. Habiendo escrito una hoja o una serie de hojas, la o el paciente podría preferir conservarlas únicamente para sí, como insumo para su proceso personal de subjetivación de la vivencia, o bien remitirlas a los y las profesionales, o a alguno de sus vínculos personales, abriéndolas a funciones múltiples. En los casos de internación, también podría elegir disponer hojas escritas en el espacio de su habitación, ante la vista de los y las demás; incluso podrían anexarse copias a su expediente.

En el paso del mapeo a la escansión y en el paso de una hoja a otra, a medida que una palabra persistiera, desapareciera o volviera a aparecer, se desplazara o se modificara (a medida que se encontrara finalmente un lugar donde alojar una palabra o, por el contrario, se la lograra expulsar; a medida que se pudiera poner alguna palabra en una relación menos dolorosa o se le encontrara un efecto benéfico), los sujetos tendrían la oportunidad de dar forma y reelaborar su experiencia corporal y subjetiva alrededor del tránsito por el espacio hospitalario, inscribiendo transformaciones, urgencias, anticipaciones, esperanzas, temores, padeceres, más allá de la exigencia de coherencia y sentido, del funcionamiento de cualquier autoridad, de la unidad de la autoría (de la exigencia de que el yo del o la paciente firmara cada palabra como propia), de la expectativa de propiedad, corrección o pertinencia, y de la necesidad práctica de hacer coincidir la palabra con los momentos procedimentales de escucha clínica. En esa posibilidad de encontrar en la palabra formas de redisposición de la experiencia hospitalaria, los sujetos podrían reubicarse a sí mismos y a quienes los rodean, ofrecer nuevos modos de vínculo terapéutico y de cuidado, así como fabricar para sí mismos el debido reparo o la debida distancia: otro lugar desde el que habitar los cuerpos expuestos. 